\title{
Caracterização do perfil lesional em ginástica artística feminina: um estudo prospectivo das ginastas Portuguesas de competição ao longo de uma época desportiva
}

\author{
Luísa Amaral 1,2 \\ Paulo Santos ${ }^{3}$ \\ José Ferreirinha ${ }^{4,5}$
}

https://doi.org/10.5628/rpcd.09.01.43

\author{
${ }^{1}$ Faculdade de Ciências da Saúde \\ Universidade Fernando Pessoa, Portugal \\ ${ }^{2}$ Centro de Medicina Desportiva do Porto, Portugal \\ ${ }^{3}$ Centro de Investigação, Formação, \\ Inovação e Intervenção em Desporto (CIFI'D) \\ Faculdade de Desporto \\ Universidade do Porto, Portugal \\ ${ }^{4}$ Universidade de Trás-os-Montes e Alto Douro, Portugal \\ ${ }^{5}$ Centro de Estudos em Desporto, Saúde e Desenvolvimento \\ Humano (CIDESD), Portugal
}

\begin{abstract}
Injury profile characterization in women's artistic gymnastics: $a$ prospective research in female elite gymnasts throughout a season

The purpose of this study was to analyze and characterize the injuries occurred during the 2006/2007 season in all competitive Portuguese gymnasts. 79 Women's Artistic Gymnastics athletes, aged between 618 years and training on average $14.15 \mathrm{~h} /$ week, were observed. The injuries were categorized according to its etiology, type, anatomic distribution, severity and apparatus occurrence. As main results we point out: (i) $43 \%$ of the gymnasts were injured, with a 2.47 lesion rate in training and 1.95 in competition; (ii) the majority of injuries were traumatic (58.3\%); (iii) the most common injury was the sprain (21.3\%); (iv) lower limbs were the most affected (53.5\%); (v) the beam was the apparatus with the highest lesion incidence (19.7\%). We concluded that there is a visible trend in the nature of injuries both in terms of its etiology and anatomical location. The trend is also evident in relation to the influence of Training load (h/week training) in the injuries appearance.
\end{abstract}

O objectivo geral deste estudo foi analisar e caracterizar as lesões ocorridas ao longo da época desportiva 2006/2007 na totalidade das ginastas portuguesas de competição. Foram observadas 79 atletas de Ginástica Artística Feminina, com idades entre os 6 e 18 anos, treinando em média 14,15h/semana. As lesões foram categorizadas em função da etiologia, tipo, distribuição anatómica, severidade e aparelho de ocorrência. Como principais resultados salienta-se: (i) $43 \%$ das atletas lesionaram-se, com uma taxa de 2,47 lesões em treino e 1,95 em competição; (ii) a maioria das lesões foi traumática

$(58,3 \%)$; (iii) a lesão mais frequente foi a entorse $(21,3 \%)$; (iv) os membros inferiores foram a região mais atingida $(53,5 \%)$;

(v) a trave olímpica foi o aparelho com maior incidência lesiva $(19,7 \%)$. Como principais conclusões, observou-se uma tendência notória na natureza das lesões tanto em função da sua etiologia, como da localização anatómica, tendência também evidente em relação à influência de algumas características de cargabilidade (h/semanais treino) no aparecimento de lesões.

Palavras-chave: ginástica artística feminina, lesões
Key-words: women artistic gymnastics, injuries 


\section{INTRODUÇÃO}

Devido à sua especificidade, a Ginástica Artística Feminina (GAF) impõe às praticantes um início de actividade desportiva antecipado. Com efeito a elevada complexidade dos movimentos técnicos e o alto grau de habilidade motora inerente a esta modalidade, faz com que seja usual as ginastas iniciarem a sua prática aos 5-6 anos de idade ${ }^{(29)}$, treinarem 2040 horas semanais $(7,11,12,16)$ e atingirem o pico de forma entre os 14-18 anos ${ }^{(2,5)}$. Decorrente do anteriormente exposto, é frequente encontrar na GAF uma elevada taxa de lesões $(3,16,26)$ que tem sido atribuída, entre outros factores, ao facto dos praticantes serem ainda crianças, adicionalmente serem crianças permanentemente submetidas a altos impactos, tanto nos treinos como nas competições(11) e por utilizarem intensidades de treino extremas $(11,16,20)$. No entanto, apesar do potencial risco de lesão, para alguns autores a ginástica artística pode ser uma modalidade relativamente segura desde que seja devidamente orientada e adoptada as indispensáveis medidas preventivas ${ }^{(22,23)}$. Neste contexto, os resultados de estudos epidemiológicos centrados na GAF poderão, eventualmente, ser um contributo fundamental para a prevenção de lesões, pelos dados que podem fornecer sobre a sua etiologia, localização anatómica, tipo e severidade, entre outros.

Em Portugal são escassos os estudos centrados na GAF, sendo mesmo inexistentes no que se refere à epidemiologia das lesões. Por este motivo, consideramos ser este um tópico de investigação prioritário de modo clarificar a incidência e prevalência das lesões na GAF, análise sem a qual não se podem retirar ilações para a sua prevenção. Deste modo, foi objectivo geral deste trabalho analisar e caracterizar todas as lesões ocorridas ao longo de uma época desportiva na totalidade das ginastas portuguesas dos vários escalões de competição. Com base neste propósito foi formulado o seguinte objectivo específico: caracterizar a natureza das lesões, por escalão etário, segundo a etiologia, a localização anatómica, o tipo, a severidade e o aparelho de ocorrência.

\section{METODOLOGIA}

\section{Amostra}

A população avaliada foi composta pela totalidade $(\mathrm{n}=79)$ das atletas de competição de GAF em
Portugal em 2006. Os dados pessoais obtidos por entrevista simples podem ser observados no Quadro 1. De acordo com a "Declaração de Helsínquia" da Associação Médica Mundial, foi obtido o consentimento informado de todos os pais das ginastas participantes neste estudo, tendo sido igualmente solicitada a autorização dos respectivos treinadores.

Quadro 1. Caracterização da totalidade da amostra $(n=79)$ de ginastas.

\begin{tabular}{lcccc}
\hline & Média & $\begin{array}{c}\text { Desvio } \\
\text { Padrão }\end{array}$ & $\begin{array}{c}\text { Valor } \\
\text { Mínimo }\end{array}$ & $\begin{array}{c}\text { Valor } \\
\text { Máximo }\end{array}$ \\
\hline $\begin{array}{l}\text { Idade Cronológica } \\
\text { (anos) }\end{array}$ & 10,03 & $\pm 2,94$ & 6,01 & 18,00 \\
\hline $\begin{array}{l}\text { Peso }(\mathrm{kg}) \\
\text { Estatura }(\mathrm{m})\end{array}$ & $1,31,74$ & $\pm 9,38$ & 18,30 & 59,70 \\
\hline $\begin{array}{l}\text { Horas de treino } \\
\text { semanais }\end{array}$ & 14,15 & $\pm 4,49$ & 6,00 & 21,00 \\
\hline $\begin{array}{l}\text { Horas de } \\
\text { competição }\end{array}$ & 11,03 & $\pm 8,72$ & 3,5 & 21,00 \\
\hline Anos de Prática & 4,04 & $\pm 2,64$ & 0,50 & 12,00 \\
\hline
\end{tabular}

As ginastas das várias idades foram reunidas em 3 grupos: Grupo I - Infantis B ( $\mathrm{n}=19 ; 7 / 8$ anos) e Infantis $A(n=26 ; 9 / 10$ anos); Grupo II - Iniciadas $(\mathrm{n}=12 ; 10 / 11$ anos) e Juvenis ( $\mathrm{n}=10 ; 12 / 13$ anos); Grupo III - Juniores ( $\mathrm{n}=5 ; 13 / 15$ anos) e Seniores ( $\mathrm{n}=7$; a partir dos 16 anos).

\section{Avaliação do perfil lesional}

Foi efectuada mensalmente uma visita aos clubes das ginastas envolvidos no estudo e recolhida informação relativa à ocorrência de lesões. Procedeu-se ao preenchimento de um formulário acerca da etiologia, localização anatómica, tipo, severidade e aparelho de ocorrência das lesões, ao longo da época desportiva 2006/07. Foi calculada a taxa de lesões por 1000 horas de exposição(5).

\section{Perfil antropométrico}

As medidas antropométricas avaliadas foram o peso, a altura, as pregas tricipital e sub-escapular e o perímetro bicipital. $\mathrm{Na}$ avaliação da composição corporal utilizou-se uma balança analógica para o peso (Tanita - Body Fat Monitor/Scale BF-574) e uma escala de medição da altura (Seca Mod 220). A partir destes parâmetros calculou-se o Índice de Massa 
Quadro 2. Número de atletas lesionadas.

\begin{tabular}{|c|c|c|c|c|}
\hline Lesões & $\begin{array}{c}\text { Grupo I } \\
\text { Infantis }(n=45)\end{array}$ & $\begin{array}{c}\text { Grupo II } \\
\text { Iniciadas/Juvenis }(n=22)\end{array}$ & $\begin{array}{c}\text { Grupo III } \\
\text { Juniores/Seniores }(n=12)\end{array}$ & $\begin{array}{l}\text { Amostra tota } \\
(n=79)\end{array}$ \\
\hline \multirow[t]{3}{*}{$\mathrm{N}^{0}$ de atletas lesionadas } & 14 & 11 & 9 & 34 \\
\hline & $17,7 \% *$ & $13,9 \%$ * & $11,4 \%$ * & $43 \% *$ \\
\hline & $31,1 \% * *$ & $50 \% * *$ & $75 \% * *$ & \\
\hline \multirow[t]{3}{*}{ Atletas sem lesões } & 31 & 11 & 3 & 45 \\
\hline & $39,2 \%$ * & $13,9 \%$ * & $3,8 \% *$ & $57 \% *$ \\
\hline & $68,9 \% * *$ & $50 \% * *$ & $25 \% * *$ & \\
\hline
\end{tabular}

* percentagem da totalidade de atletas lesionadas; ${ }^{* *}$ percentagem de atletas lesionadas por escalões

Corporal - IMC $\left(\mathrm{Kg} / \mathrm{m}^{2}\right)$. A medição das pregas subcutâneas foi realizada com compassos do tipo Harpenden em dois pontos: prega cutânea tricipital e sub-escapular, fundamentada por Janz et al.(15) e Heyward e Stolarczyk ${ }^{(14)}$ quando se referem à equação de Slaughter et al.(ver ref. 14) para estimar a percentagem de gordura corporal (Gc) em crianças. $\mathrm{O}$ Perímetro Bicipital foi medido com uma fita "Harpenden Anthropometric Tape" 2m. Para a determinação da massa gorda e massa isenta de gordura (MIG) ou massa magra, utilizámos as fórmulas propostas por Malina et al.(19): massa gorda $=$ peso corporal $\mathrm{x} \%$ gordura; $\mathrm{MIG}=$ peso corporal - massa gorda. Para avaliar a massa muscular (MM) foram aplicadas as fórmulas de Heymsfield(13).

\section{Procedimentos Estatísticos}

No estudo de caracterização da amostra utilizou-se a média (), desvio-padrão (dp), valores mínimos (min) e máximos (max). Para a comparação entre os grupos I, II e III (Infantis, Iniciadas/Juvenis, Juniores/Seniores) da frequência de lesões recorreuse à ANOVA One-Way. Na determinação de valores estatisticamente significativos entre os pares aplicou-se o Post-hoc de Bonferroni.

Com o objectivo de testar a influência das variáveis de prática desportiva (anos de prática e número de horas de treino por semana)no ter ou não ter lesão recorreu-se á utilização da regressão logística. $\mathrm{O}$ nível de significância estatístico foi mantido em $5 \%$ $(\mathrm{p} \leq 0,05)$.

\section{RESULTADOS}

Caracterização da natureza das lesões ocorridas no total de ginastas e nos diferentes grupos etários

No Quadro 2 pode observar-se que $43 \%(n=34)$ das atletas pesquisadas apresentaram lesões durante $o$ período de observação. Feita a análise por escalão, encontrou-se um valor claramente superior nas atletas mais velhas (75\% no grupo III) comparativamente às mais novas $(31,1 \%$ no grupo I e $50 \%$ no grupo II). Com efeito, a grande maioria das atletas que não apresentou qualquer tipo de lesão pertencia ao grupo I. No Quadro 3, relativo à etiologia das lesões, pode observar-se que, à semelhança do descrito no quadro 2 , também aqui o grupo III $(52,8 \%)$ registou o número mais elevado de lesões (67 num total de 127). Do mesmo modo, o grupo I continuou a evidenciar o valor mais baixo (22), apesar do maior número de elementos que o constitui $(n=45)$.

Quadro 3. Etiologia das lesões.

\begin{tabular}{lcccc}
\hline Lesões & Grupo I & Grupo II & Grupo III & $\begin{array}{c}\text { Amostra } \\
\text { total }\end{array}$ \\
\hline Súbitas/Traumáticas & 13 & 21 & 40 & 74 \\
$\%$ Total & $10,2 \%$ & $16,5 \%$ & $31,5 \%$ & $58,3 \%$ \\
$\%$ Por Grupo & $59,1 \%$ & $55,3 \%$ & $59,7 \%$ & \\
\hline Gradual/Sobreuso & 9 & 17 & 27 & 53 \\
$\%$ Total & $7,1 \%$ & $13,4 \%$ & $21,3 \%$ & $41,7 \%$ \\
$\%$ Por Grupo & $40,9 \%$ & $44,7 \%$ & $40,3 \%$ & \\
\hline Total & 22 & 38 & 67 & 127 \\
$\%$ Total & $17,3 \%$ & $29,9 \%$ & $52,8 \%$ & $100 \%$ \\
$\%$ Por Grupo & $100 \%$ & $100 \%$ & $100 \%$ & \\
\hline
\end{tabular}


Quanto à etiologia das lesões, constatou-se que a maioria $(58,3 \%)$ ocorreu de forma súbita, sendo estas consideradas lesões traumáticas. As restantes $(41,7 \%)$ tiveram um início gradual, e resultaram do sobreuso das estruturas anatómicas. O grupo III registou a maior percentagem $(59,7 \%)$ de lesões traumáticas e o Grupo II $(44,7 \%)$ de lesões de sobreuso, no entanto, os valores percentuais nos três grupos foram idênticos, não tendo sido observadas diferenças significativas.

Quadro 4. Local de ocorrências das lesões.

\begin{tabular}{lcccc}
\hline $\begin{array}{l}\text { Lesões } \\
\text { total }\end{array}$ & Grupo I & Grupo II & Grupo III & Amostra \\
\hline $\begin{array}{l}\text { Treino/Prática } \\
\% \text { Total }\end{array}$ & 21 & 35 & 61 & 117 \\
$\%$ Por Grupo & $16,5 \%$ & $27,6 \%$ & $48 \%$ & $92,1 \%$ \\
\hline Competição & $95,5 \%$ & $92,1 \%$ & $91,0 \%$ & \\
$\%$ Total & 0 & 1 & 6 & 7 \\
$\%$ Por Grupo & $0 \%$ & $0,8 \%$ & $4,7 \%$ & $5,5 \%$ \\
\hline Fora do Ginásio & $0 \%$ & $0,03 \%$ & $9,0 \%$ & \\
$\%$ Total & 1 & 2 & 0 & 3 \\
$\%$ Por Grupo & $0,8 \%$ & $1,6 \%$ & $0 \%$ & $2,4 \%$ \\
\hline Total & $4,5 \%$ & $0,06 \%$ & $0 \%$ & \\
$\%$ Total & 22 & 38 & 67 & 127 \\
$\%$ Por Grupo & $17,3 \%$ & $30 \%$ & $52,7 \%$ & $100 \%$ \\
\hline & $100 \%$ & $100 \%$ & $100 \%$ & \\
\hline & & & &
\end{tabular}

Relativamente à ocorrência das lesões (Quadro 4), em termos absolutos, estas ocorreram maioritariamente durante o treino $(92,1 \%)$, com valores muito semelhantes nos três escalões (entre 91-95,5\%). Apenas $5,5 \%$ aconteceram durante as competições e quase todas no grupo III. O Quadro 5 indica a taxa lesiva da época desportiva 2006/07, com base na média de horas de treino e de competição. A taxa de lesões na presente amostra em treino e competição foi de 2,47 e 1,95 , respectivamente, com o grupo III a apresentar sempre os valores mais elevados $(6,77$ e 23,8$)$.

Quadro 5. Taxa de lesões em treino e em competição.

\begin{tabular}{lcccc}
\hline $\begin{array}{l}\text { Taxa de lesões } \\
\text { total }\end{array}$ & Grupo I & Grupo II & Grupo III & Amostra \\
\hline Em treino $(/ 1000 \mathrm{~h})^{*}$ & 0,86 & 2,31 & 6,77 & 2,47 \\
\hline Em competição ${ }^{*}$ & 0 & 2,16 & 23,80 & 1,95
\end{tabular}

*Taxa de lesões =

$n^{0}$ total de lesões sofridas pelas ginastas num determinado período de tempo x1000 $n^{\circ}$ total de horas de treino

Quanto à tipologia das lesões (Quadro 6), em termos globais, as entorses foram as afecções mais frequentes $(21,3 \%)$, seguidas pelas contusões $(18,9 \%)$ e contracturas $(17,3 \%)$. Na análise por escalões, as contracturas foram as mais frequentes $(27,3 \%)$ no grupo I, as lesões na cartilagem de crescimento $(21,1 \%)$ no grupo II e as contusões $(25,4 \%)$ e entorses $(23,9 \%)$ no grupo III.

Quadro 6. Tipo de lesões.

\begin{tabular}{|c|c|c|c|c|}
\hline $\begin{array}{l}\text { Lesões } \\
\text { total }\end{array}$ & Grupo I & Grupo II & Grupo III & Amostra \\
\hline Contracturas & 6 & 6 & 10 & 22 \\
\hline$\%$ Total & $4,7 \%$ & $4,7 \%$ & $7,9 \%$ & $17,3 \%$ \\
\hline$\%$ Por Grupo & $27,3 \%$ & $15,8 \%$ & $14,9 \%$ & \\
\hline Cartilagens de Crescimento & 2 & 8 & 6 & 16 \\
\hline$\%$ Total & $1,6 \%$ & $6,3 \%$ & $4,7 \%$ & $12,6 \%$ \\
\hline$\%$ Por Grupo & $9,1 \%$ & $21,1 \%$ & $9,0 \%$ & \\
\hline Contusões & 2 & 5 & 17 & 24 \\
\hline$\%$ Total & $1,6 \%$ & $3,9 \%$ & $13,4 \%$ & $18,9 \%$ \\
\hline$\%$ Por Grupo & $9,1 \%$ & $13,2 \%$ & $25,4 \%$ & \\
\hline Entorses & 4 & $?$ & 16 & 27 \\
\hline$\%$ Total & $3,1 \%$ & $5,5 \%$ & $12,6 \%$ & $21,3 \%$ \\
\hline$\%$ Por Grupo & $18,2 \%$ & $18,3 \%$ & $23,9 \%$ & \\
\hline Estiramentos & 3 & 3 & 8 & 14 \\
\hline$\%$ Total & $2,4 \%$ & $2,4 \%$ & $6,3 \%$ & $11,0 \%$ \\
\hline$\%$ Por Grupo & $13,6 \%$ & $7,9 \%$ & $11,9 \%$ & \\
\hline Fracturas & 4 & 3 & 0 & 7 \\
\hline$\%$ Total & $3,1 \%$ & $2,4 \%$ & $0 \%$ & $5,5 \%$ \\
\hline$\%$ Por Grupo & $18,2 \%$ & $7,9 \%$ & $0 \%$ & \\
\hline Inflamações & 0 & 5 & 10 & 15 \\
\hline$\%$ Total & $0 \%$ & $3,9 \%$ & $7,9 \%$ & $11,8 \%$ \\
\hline$\%$ Por Grupo & $0 \%$ & $13,2 \%$ & $14,9 \%$ & \\
\hline Sub-lux /Luxações & 1 & 1 & 0 & 2 \\
\hline$\%$ Total & $0,8 \%$ & $0,8 \%$ & $0 \%$ & $1,6 \%$ \\
\hline$\%$ Por Grupo & $4,5 \%$ & $2,6 \%$ & $0 \%$ & \\
\hline Total & 22 & 38 & 67 & 127 \\
\hline$\%$ Total & $17,3 \%$ & $29,9 \%$ & $52,8 \%$ & $100 \%$ \\
\hline$\%$ Por Grupo & $100 \%$ & $100 \%$ & $100 \%$ & \\
\hline
\end{tabular}


Relativamente à localização anatómica das lesões, mais de metade $(53,5 \%)$ ocorreu nos membros inferiores, $24,4 \%$ nos membros superiores, $17,3 \%$ na coluna e 4,7\% no tronco. Quanto à localização corporal, o calcâneo foi o local anatómico mais atingido $(14,2 \%)$, seguido da tíbio-társica $(11,0 \%)$, da coluna dorsal $(9,4 \%)$, do joelho e punho $(8,7 \%)$, dos pés/dedos (7,9\%), da coluna lombar $(7,1 \%)$ e da coxa $(6,3 \%)$. Os locais menos atingidos foram o antebraço $(4,7 \%)$, o ombro, as mãos/dedos e anca $(3,9 \%)$, o cotovelo e abdómen $(3,1 \%)$, a perna e costelas $(1,6 \%)$ e a coluna cervical $(0,8 \%)$.

Verificou-se uma prevalência das lesões traumáticas relativamente às de sobreuso no membro inferior $(40,2 \%$ versus $13,4 \%)$ e no tronco $(4,7 \%$ versus $0 \%)$. No entanto, observou-se uma prevalência das lesões crónicas relativamente às agudas no membro superior $(14,2 \%$ versus $10,2 \%)$ e na coluna $(14,2 \%$ versus $3,1 \%)$. Relativamente à influência das lesões na actividade dos ginastas, observou-se que a grande maioria $(83,5 \%)$ dos traumatismos sofridos causou limitações na actividade. Com efeito, apenas 16,5\% das lesões não se traduziram por restrições ao treino.

Quadro 7 - Categorias relativas à severidade das lesões.

\begin{tabular}{lcccc}
\hline & Grupo I & Grupo II & Grupo III & $\begin{array}{c}\text { Amostra } \\
\text { total }\end{array}$ \\
\hline Severidade Ligeira * & 5 & 8 & 21 & 34 \\
$\%$ Total & $3,9 \%$ & $6,3 \%$ & $16,5 \%$ & $26,8 \%$ \\
$\%$ Por Grupo & $22,7 \%$ & $29,6 \%$ & $36,8 \%$ & \\
\hline Severidade Moderada ** & 11 & 9 & 19 & 39 \\
$\%$ Total & $8,7 \%$ & $7,1 \%$ & $15 \%$ & $30,7 \%$ \\
$\%$ Por Grupo & $50,0 \%$ & $33,4 \%$ & $33,4 \%$ & \\
\hline Severidade Grave *** & 6 & 10 & 17 & 33 \\
$\%$ Total & $4,7 \%$ & $7,9 \%$ & $13,4 \%$ & $26 \%$ \\
$\%$ Por Grupo & $27,3 \%$ & $37,0 \%$ & $29,8 \%$ & \\
\hline
\end{tabular}

* 1 a 7 dias de recuperação; ** 8 a 21 dias de recuperação; *** mais de 21 dias de recuperação

Relativamente à severidade das lesões (Quadro 7) constatou-se que, em termos globais, a maioria das lesões apresentou uma severidade moderada (30.7\%). Já no que respeita à análise por grupo, a maioria (50\%) das lesões no grupo I apresentou uma severidade moderada, no grupo II grave $(37,0 \%)$ e no grupo III ligeira $(36,8 \%)$.
Quadro 8. Ocorrência de lesões por aparelho.

\begin{tabular}{lcccc}
\hline & Grupo I & Grupo II & Grupo III & $\begin{array}{c}\text { Amostra } \\
\text { total }\end{array}$ \\
\hline Solo & 5 & 6 & 9 & 20 \\
$\%$ Total & $3,9 \%$ & $4,7 \%$ & $7,1 \%$ & $15,7 \%$ \\
$\%$ Por Grupo & $71,4 \%$ & $37,5 \%$ & $21,4 \%$ & \\
\hline Trave & 1 & 5 & 19 & 25 \\
$\%$ Total & $0,8 \%$ & $3,9 \%$ & $15 \%$ & $19,7 \%$ \\
$\%$ Por Grupo & $14,3 \%$ & $31,2 \%$ & $45,2 \%$ & \\
\hline Paralelas & 1 & 2 & 12 & 15 \\
$\%$ Total & $0,8 \%$ & $1,6 \%$ & $9,4 \%$ & $11,8 \%$ \\
$\%$ Por Grupo & $14,3 \%$ & $12,5 \%$ & $28,6 \%$ & \\
\hline Salto de Cavalo & 0 & 3 & 2 & 5 \\
$\%$ Total & $0 \%$ & $2,4 \%$ & $1,6 \%$ & $3,9 \%$ \\
$\%$ Por Grupo & $0 \%$ & $18,8 \%$ & $4,8 \%$ & \\
\hline No Total de lesões & 7 & 16 & 42 & 65 \\
nos aparelhos & & & & \\
$\%$ Total & $5,5 \%$ & $12,6 \%$ & $33,1 \%$ & $51,2 \%$ \\
$\%$ Por Grupo & $100 \%$ & $100 \%$ & $100 \%$ & \\
\hline
\end{tabular}

Dos $51 \%$ de ginastas que sofreram traumatismos nos diferentes aparelhos (Quadro 8), a maioria lesionou-se na trave olímpica $(19,7 \%)$ e solo $(15,7 \%)$, tendo o salto de cavalo registado o menor número de lesões (3,9\%). Já comparando as lesões ocorridas nos diferentes grupos, verificou-se que a maior parte destas ocorreu no grupo I nos exercícios de solo $(71,4 \%)$.

\section{Caracterização do perfil morfológico}

No Quadro 9 podem ser observados os valores médios dos vários indicadores antropométricos e de composição corporal utilizados na caracterização morfológica da nossa amostra.

Quadro 9. Caracterização antropométrica das ginastas.

\begin{tabular}{lcccc}
\hline & Média & $\begin{array}{c}\text { Desvio } \\
\text { Padrão }\end{array}$ & Mínimo & Máximo \\
\hline Peso (kg) & 31,74 & 9,38 & 18,30 & 59,70 \\
Estatura (m) & 1,36 & 0,12 & 1,12 & 1,59 \\
Índice Massa Corporal (IMC) $\left(\mathrm{kg} / \mathrm{m}^{2}\right)$ & 16,90 & 2,35 & 13,14 & 24,07 \\
Gordura Corporal (GC) (\%) & 15,23 & 3,40 & 9,71 & 27,47 \\
Massa Isenta Gordura (MIG) (\%) & 84,77 & 3,40 & 72,50 & 90,30 \\
Massa Muscular (MM) (\%) & 11,01 & 2,20 & 6,47 & 16,28 \\
\hline
\end{tabular}


Da análise do Quadro 10 constatou-se que os três grupos apresentaram um número de lesões diferenciado $(p=0,00)$. Utilizando o teste de Post-Hoc de Bonferroni encontraram-se diferenças entre o grupo III e os grupos I $(p=0,00)$ e II $(p=0,00)$. Com efeito, as atletas do grupo III apresentaram uma maior ocorrência de lesões relativamente aos grupos I $(5,58$ vrs. 0,49$)$ e II $(5,58$ vrs. 1,73$)$.

Quadro 10. Comparação múltipla entre grupos relativamente ao de número de lesões $\left({ }^{*} p=0,05\right]$.

\begin{tabular}{cccccc}
\hline & Grupo I & Grupo II & Grupo III & $F$ & $p$ \\
\hline NN$^{0}$ de lesões & $0,49 \pm 0,86$ & $1,73 \pm 2,0$ & $5,58 \pm 4,7$ & 26,11 & $0,00^{*}$ \\
\hline
\end{tabular}

O Quadro 11 apresenta os resultados do modelo de regressão logística em que foram incluídas as variáveis de prática desportiva com o objectivo de testar a sua influência no "ter" ou "não ter" lesão. Pela observação dos efeitos principais de cada uma das variáveis explicativas, constatou-se o seguinte: (1) as ginastas Infantis têm menor probabilidade de contraírem uma lesão relativamente às Juniores/Seniores; (2) quanto maior o número de anos de prática, o número de $\mathrm{h} /$ semanais de treino, maior a possibilidade das ginastas contraírem uma lesão.

Quadro 11. Resultados do Modelo de regressão logística para testar a sua influência em "ter" ou "não ter" lesão [ $\left.{ }^{*} p=0,05\right]$.

\begin{tabular}{lcc}
\hline & \multicolumn{2}{c}{$\begin{array}{l}\text { Odds Ratio (0R) } \\
(95 \% \text { Intervalo de Confiança) }\end{array}$} \\
\hline Variáveis explicativas & Bruto & $\mathrm{P}^{*}$ \\
\hline $\begin{array}{l}\text { Escalão Etário } \\
\text { Grupo III (a) }\end{array}$ & 1 & \\
\hline Grupo II & $0,33(0,07-1,57)$ & 0,17 \\
\hline Grupo I & $0,15(0,04-0,64)$ & $0,01^{*}$ \\
\hline Anos Prática & $1,43(1,16-1,76)$ & $0,00^{*}$ \\
\hline horas/semanais de treino & $1,42(1,20-1,69)$ & $0,00^{*}$ \\
\hline
\end{tabular}

(a) Classe de Referência (Juniores/Seniores)

\section{DISCUSSÃO}

\section{Perfil lesional}

Para alguns autores a ginástica é uma modalidade potencialmente indutora de lesões(11), tendo sido referido que a taxa anual de lesões na GA é das mais elevadas no desporto feminino $(16,18)$ ou mesmo que o risco lesivo duplica relativamente a outras modalidades desportivas (20). De acordo com a National Collegiate Athletic Association (NCAA) (21), a ginástica ocupa o segundo lugar do ranking quanto à taxa e à severidade das lesões, com 6,2 lesões por $1000 \mathrm{~h}$ de exposição e com lesões que ocasionam mais de 7 dias de restrição da actividade, valor próximo da taxa lesiva encontrada no grupo III $(6,8)$ do nosso estudo. $\mathrm{Na}$ apreciação da taxa de lesões em $1000 \mathrm{~h}$ de práti$\mathrm{ca}$, verificou-se que na globalidade das atletas, a taxa de ocorrência de lesões no treino $(2,47)$, foi superior à da competição $(1,95)$, valores condizentes com os valores apresentados por diversos autores $(5,17,18)$. No entanto, apesar de nos grupos I e II a taxa de lesões, em treino e competição, ter sido similar, essa tendência não se verificou no grupo III, com uma taxa lesiva muito superior na competição $(23,80$ vrs 6,77). A NCAA 1993/94 também menciona que o risco lesivo é normalmente 3 vezes superior em competição(8).

Também os anos totais de prática, quando analisados independentemente de outras variáveis, se mostraram influentes no aparecimento de lesões (OR: 1,43; IC95\%: 1,16-1,76). De facto, os nossos resultados evidenciaram que quanto maior for o número de anos de prática de uma ginasta, tanto maior será a predisposição para o aparecimento de lesões. De forma similar, as horas de prática semanal das ginastas potenciam o aparecimento de lesões ${ }^{(1)}$.

Efectivamente, ao utilizar o modelo de regressão logística, concluímos igualmente que quanto maior for o número de horas de treino semanal, tanto maior será a hipótese da ginasta contrair uma lesão (OR: 1,42; IC95\%: 1,20-1,69).

Adicionalmente, tal como referido por Kirialanis et al.(16), verificámos que as atletas lesionadas treinavam mais horas por semana do que as não lesionadas.

Relativamente à etiologia das lesões, os valores médios encontrados para as lesões traumáticas $(58,3 \%)$ e de sobreuso $(41,7 \%)$ encontram-se dentro dos intervalos referidos por diversos autores $(5,12,16,17,18,25,28)$. Os nossos resultados sugerem que as atletas com maior volume e anos de treino, maior coeficiente de dificuldade nos exercícios e um 
perfil lesional anterior mais acentuado, evidenciam uma maior predisposição para contrair lesões de sobreuso. De facto, o grupo I apresentou o número mais baixo de lesões deste tipo $(7,1 \%)$, com as Infantis B a não apresentaram mesmo qualquer lesão de sobreuso, o que está de acordo com a literatura que define uma relação positiva entre a quantidade de tempo dispendida no ginásio e as lesões crónicas por acumulação de microtraumas ${ }^{(20,25)}$. Com efeito, o tipo, a frequência, a intensidade e a duração do treino revelam um papel importante na etiologia das lesões de sobreuso(24). Deste modo, as ginastas podem ter lesões de sobreuso apenas pela necessidade de repetição de certas rotinas, centenas ou milhares de vezes, até obterem consistência nos seus gestos e exercícios.

Relativamente à localização anatómica das lesões, o nosso estudo seguiu a tendência encontrada na literatura $(3,5,8,12,17,20)$, com mais de metade $(53,5 \%)$ das afecções a atingirem o membro inferior, seguindo-se o membro superior $(24,4 \%)$, a coluna vertebral $(17,3 \%)$ e o tronco $(4,7 \%)$. Mais detalhadamente, os locais mais predispostos às lesões foram o calcâneo e a articulação tíbio-társica, confirmando os resultados de Dixon e Fricker(12) que referem as entorses da tíbio-társica como as lesões mais frequentes do membro inferior. Esta predisposição pode, em grande medida, ser justificada pelo alto impacto típico desta modalidade, tanto nas recepções como nas constantes impulsões, ao que acresce a necessidade de manter permanentemente o controlo proprioceptivo de forma a assegurar o equilíbrio em qualquer situação. Já no que se refere ao membro superior, o punho $(8,7 \%)$ foi claramente o local mais atingido, uma vez que as extremidades superiores são utilizadas tanto como membros de suporte, como receptores de alto impacto. Relativamente à coluna vertebral, a região mais afectada foi a região dorsal $(9,4 \%)$ seguida da lombar $(7,1 \%)$, resultados ligeiramente diferentes das pesquisas de Wadley e Albright ${ }^{(28)}$ e de Caine ${ }^{(3)}$ que referem o segmento lombar como o mais afectado. As causas dos sintomas na coluna das ginastas são a consequência de posturas repetidas de flexão e hiper-extensão durante os voos, saídas e mortais, associadas a posturas hiperlordóticas com fortes cargas de impacto vertical durante as recepções(3).
Quanto à tipologia das lesões, o número elevado de contracturas, entorses e fracturas observadas nas ginastas mais novas, poderá eventualmente estar relacionado com diferentes factores entre os quais poderíamos referir a utilização de gestos inadequados, falta de controlo corporal, laxidez ligamentar, desequilíbrios musculares, factores proprioceptivos, ou mesmo imaturidade óssea. Waddington(27) refere precisamente que a fase de crescimento em que se encontram as atletas, está relacionada com a particular susceptibilidade a certos tipos de lesões, nomeadamente luxações e fracturas. Nestes escalões, as atletas estão numa etapa de aquisição de habilidades/coordenação e numa fase de desenvolvimento espaço-temporal. Portanto, tanto a falta de domínio no aparelho como as constantes situações de aprendizagem podem ser igualmente a causa destas lesões traumáticas. Já no caso das atletas Juniores/Seniores, com um nível de controlo corporal e proprioceptivo superior, esperávamos encontrar maioritariamente lesões mais severas, tais como fracturas e luxações, no entanto não se observou nenhuma ocorrência desse tipo. De facto, as contusões e as entorses foram as lesões de maior incidência no grupo III, possivelmente em consequência do grande número de impulsões e recepções.

Relativamente às lesões nas cartilagens de crescimento, verificámos que as ginastas mais velhas, contrariamente ao esperado, também as contraem, provavelmente por ainda não terem atingido a maturidade óssea e sexual. Deste modo, torna-se relevante conhecer as fases de desenvolvimento de cada ginasta, em particular, e não trabalhar somente em função da idade cronológica. No caso de imaturidade óssea, em que a jovem ginasta ainda não atingiu o termo do seu crescimento e não apresenta uma ossificação completa, o limite de tolerância das epífises pode ser excedido por mecanismos de stress inerentes à modalidade $(6,10)$. Nesta fase, poderá ser pertinente proteger as cartilagens articulares das forças de compressão, de deslize e de rotação, reduzindo o número de repetições consecutivas, utilizando mais o trampolim, utilizando protecções e treinando flexibilidade durante o pico de salto de crescimento.

Em relação à severidade das lesões, os resultados da nossa pesquisa são semelhantes aos referenciados na literatura(5,16): 26,8 - 40,8\% para as ligeiras; 33,3 - 
$44,0 \%$ para as moderadas; $25,9-29,0 \%$ para as graves. Quanto à ocorrência de lesões por aparelho, a literatura refere, por ordem decrescente de importância, o solo $(33,9-47,7 \%)$, a trave $(17,4-23,1 \%)$, as paralelas $(9,2-20,0 \%)$ e o salto de cavalo $(12,8-$

$14,5 \%)(16,18,20,25)$. Em termos globais, a trave revelouse o aparelho mais lesivo, particularmente no grupo III onde foi responsável por $45.2 \%$ das lesões (especialmente contusões nos pés). Já nos grupos I e II os resultados foram similares aos da literatura, com o solo a apresentar o maior número de lesões, especialmente no grupo I $(71,4 \%)$. O solo é particularmente traumático porque é o local onde se realiza a aprendizagem da maioria das habilidades, com as forças (nas impulsões e recepções) a variarem entre 5 e 17,5 vezes o peso do corpo (26).

Para concluir, existem tendências gerais notórias na natureza das lesões ocorridas nas ginastas portuguesas, tanto em função da sua etiologia (eminentemente traumática), como da localização anatómica (envolvendo principalmente a articulação tíbio-társica e o calcâneo). Finalmente, constatou-se a influência de cargabilidade ( $\mathrm{h} /$ semanais treino) no aparecimento de lesões.

\section{CORRESPONDÊNCIA}

\section{Luísa Amaral}

Faculdade de Ciências da Saúde

Universidade Fernando Pessoa

Rua Carlos Maia, 296

4200-150 Porto

E-mail: lamaral@ufp.edu.pt 


\section{REFERÊNCIAS BIBLIOGRÁFICAS}

1. Armstrong N, Mechelen W (2000). Paediatric Exercise Science and Medicine.Oxford: Press, O.U.

2. Bompa T (1990). Theory and Methology of training.lowa: Kendall Hunt Publishing Company.

3. Caine D (2003). Injury Epidemiology. in: Sands, W.A., Caine, D.J., and Borms, J. (ed.). Scientific Aspects of Women's Gymnastics, vol. 45. Basel:Karger, 72-109

4. Caine D, Bass S, Daly R (2003). Does elite competition inhibit growth and delay maturation in some gymnasts? Quite possibly. Ped. Exerc. Sci. 15: 360-372.

5. Caine D, Cochrane B, Caine C, Zemper E (1989). An epidemiological investigation of injuries affecting young competitive female gymnasts. Am. J. Sports Med. 17: 811-820.

6. Caine D, DiFiori J, Maffulli N (2006). Physeal injuries in children's and youth sports: reasons for concern? . $\mathrm{Br}$ J. Sports Med. 40: 749-760.

7. Caine D, Lewis P, O'Connor W, Howe W, Bass S (2001). Does gymnastics training inhibit growth of females? . Clin. J. Sport Med. 11: 260-270.

8. Caine D, Lindner K, Mandelbaum B, Sands W (1996). Gymnastics. in: Caine, D., Caine, C., and Lindner, K. (ed.). Epidemiology of sports injuries, Champaign, IL: Human Kinetics, 213-246

9. Caine D, Roy S, Singer K, Broekhoff J (1992). Stress changes of the distal radial growth plate: A radiographic survey and review of the literature. Am J. of Sports Med. 20: 290298.

10. Commandre F, Personne J, Taillan B, Peretti F, Argenson C, Ealaqui M (1985). A propos des risques de l'entrainement intensif précoce sur l'appareil locomoteur. E.S.I.P. 346-350.

11. Daly R, Bass S, Finch C (2001). Balancing the risk of injury to gymnasts: how effective are the counter measures? $\mathrm{Br}$ J Sports Med. 35: 8-18.

12. Dixon M, Frricker P (1993). Injuries to elite gymnasts over 10 yr. Med. Sci. Sports Exer. 25: 1322-1329.

13. Heymsfield S, McManus C, Smith J, Stevens V, Nixon D (1982). Anthropometric measurement of muscle mass: revised equations for calcutating bone-free arm muscle area. Am. J. Clin. Nutr. 32: 1834-1840.

14. Heyward V, Stolarczyk L (1996). Applied body composition assessment. Champaign, IL: Human Kinetics.
15. Janz K, Nielsen D, Cassady S, Cook J, Tai Wu Y, Hansen J (1993). Cross-validation of the Slaughter skinfold equations for children and adolescents. Med Sci Sports Exerc. 25: 1070-1076.

16. Kirialanis P, Malliou P, Beneka A, Gourgoulis V, Giofstidou A, Godolias G (2002). Injuries in artistic gymnastic elite adolescent male and female athletes. J Back Musculoskeletal Rehabil. 16: 145-151.

17. Kolt G, Kirkby R (1999). Epidemiology of injury in elite and subelite female gymnasts: A comparation of retrospective and prospective findings. Br J. Sports Med. 33: 312-318.

18. Lindner K, Caine D (1990). Injury patterns of female competitive club gymnasts. Can. J. Sport Sci. 15: 254-261.

19. Malina R, Bouchard C, Bar-Or O (2004). Growth, Maturation, and Physical Activity. Champaign, IL: Kinetics, $\mathrm{H}$.

20. McAuley E, Hudash G, Shields K, Albright J, Garrick J, Requa R, Wallace R (1987). Injuries in women's gymnastics: the state of the art. Am. J. Sports Med. 15: 558-565.

21. National Collegiate Athletic Association (2002-2003). NCAA Sports Medicine Handbook, 15th ed. in: National Collegiate Athletic Association (2002). Indianapolis

22. Nista-Piccolo V (2005). Pedagogia da ginástica artística. in: Nunomura, M. and Nista-Piccolo, V. (ed.). Compreendendo a Ginástica Artística, vol. 1. S. Paulo:Phorte Editora, 27-36

23. Nunomura M (2002). Lesões na Ginástica Artística: Principais incidências e medidas preventivas. Motriz. 8: 2129.

24. Parkkari J, Kujala U, Kannus P (2001). Is it possible to prevent sports injuries? Review of Controlled Clinical Trials and Recommendations. Sports Med. 31: 985-995.

25. Petronne F, Ricciardelli E (1987). Gymnastic injuries: Virginia experience 1982-1983. Am J Sports Med. 15 59-62.

26. Sands W (2000). Injury prevention in women's gymnastics. Sports Med. 30: 359-373.

27. Waddington I (2000). Sport, Health and Drugs: A critical Sociological Perspective. London: E \& FN Spon.

28. Wadley G, Albright J (1993). Women's intercollegiate gymnastics. Injury patterns and "perpanent" medical disability. Am J Sports Med. 21: 314-320.

29. Zetaruk M (2000). The young gymnast. Clin Sports Med. 19: 757-780. 